\title{
Exploring Social Sustainability: \\ Learning from perspectives on Urban Development and Companies and Products
}

\author{
Carina Weingaertner \& Åsa Moberg
}

\begin{abstract}
There is a fragmented approach to social sustainability in the literature, and this paper aims at contributing to a better understanding of the meanings and interpretations of that concept whilst reviewing and discussing the social dimension of sustainability from the perspectives of two fields: urban development as well as companies and products. The analysis identifies commonalities and differences in the understanding of the conceptualization of social sustainability and helps identify core aspects which cross disciplinary boundaries. Although there are a number of similarities between the fields, compiling a list of aspects that is representative of social sustainability is not straightforward, as interpretations are context dependant and aspects are often closely interconnected. Differences are frequently due to variations in scoping and context, or whether or not a life cycle perspective is used. Nonetheless, there seems to be an underlying common understanding of what social sustainability is, and a set of key themes (social capital, human capital and well-being) is suggested as an alternative to put more specific measures and indicators in perspective. However, context specific information is still necessary in practical applications.
\end{abstract}

Key words: social sustainability, definitions, key aspects, urban development, company and products perspective

\section{Introduction}

Since its popularization by the Brundtland Commission (WCED 1987), the conceptualization and theorization of what sustainable development (SD) means is abundant in the literature (WECD 1987, Elliot 1999, Redclift 2005a, Jabareen 2008). Some argue that the over-utilization but simultaneous under-theorization of 'sustainable development' as a concept means that it can lend itself to a range of very divergent goals (Le Heron 2006: 441, Marcuse, 1998), others consider that its strength lies precisely in the fact that there is no centrally determined blueprint for sustainable development, and thus its meaning will have to emerge out of an interactive process of dialogue and reflection (Jordan 2008, Faucheux et al. 1998: 1-6). Many agree that a universal and 
context-independent definition for 'sustainable development' may not be possible (Koning 2002, Redclift 2005b, Jordan 2008, Connelly 2007), and as Haughton and Counsell put it, "rather than focus on searching for a definitive meaning of 'sustainable development' ... it is necessary to recognize the multiplicities of sustainabilities and to analyse the ways in which these are shaped" (Haughton \& Counsell 2004: 72-73)

The terms 'sustainable development' and 'sustainability' are often used interchangeably. However we understand SD to refer to a process of change towards achieving sustainability goals, whereas sustainability, or the 'ability to sustain' (Marcuse 1998), refers to an (often ideal) end-state that can be sustained over time. Defining and discussing what sustainability is, will help us understand how the process of sustainable development should be shaped. The focus of this paper is not on the sustainable development process, but rather aspects that help identify what characterizes sustainability, particularly considering the social aspects.

A review of the literature revealed that, despite the extensive body of literature on the social dimension of sustainability, there is still need for a better understanding of the meanings and interpretations of that concept, in particular when considering it from a cross-disciplinary perspective. Thus this paper aims at contributing to the debate by reviewing and discussing the ways in which social sustainability is presented, from the perspectives of two diverse fields: urban development, and company and products. These fields were deliberately chosen as they are often managed by contrasting groups of stakeholders: urban development is strongly led by the public sector whereas companies and products are generally led by private interests. Analysing and comparing the conceptualization of social sustainability within these contrasting fields should also help identify core themes, which cross disciplinary boundaries. Both in academia and with practitioners, interdisciplinary work is evermore present, and it is expected that this kind of analysis will help clarify disciplinary understandings on the subject, and enable people to work together more effectively.

The paper proceeds as follows: in the next section we review and explore the literature on social sustainability from the two contrasting perspectives. This is followed by an analysis and discussion of commonalities and differences in the urban development and company and products' approaches. To conclude we briefly consider ways in which both fields can benefit from each other's understanding of social sustainability.

\section{Social Sustainability - reviewing and defining}

It should come as no surprise that there is no single blueprint definition to social sustainability, and the definitions that exist are often derived according to disciplinespecific criteria or study perspectives, rather than being general. For example Sachs states that social sustainability 'must rest on basic values of equity and democracy' (Sachs 1999:27), while Barbier (1987) and Konning (2002) focus on the importance of maintaining social values such as culture, equity and social justice. From a sociological standpoint, Littig and Griessler stress the importance of 'work' and 'needs', but also highlight the relations between nature and society by stating that "Social sustainability is given, if work within a society and the related institutional arrangements satisfy an extended set of human needs [and] are shaped in a way that nature and its reproductive 
capabilities are preserved over a long period of time and the normative claims of social justice, human dignity and participation are fulfilled." (2005:72). Rather than providing a conceptual definition, others have proposed key themes or topics that describe social issues relevant to the sustainability debate (The UNSD Website. 2010). In addition there are also the Millennium Development Goals (MDGs) which represent human needs and basic rights that every person should enjoy, and they include: to end extreme poverty and hunger, universal primary education, promote gender equality and women empowerment, reduce child mortality, improve maternal health, combat HIVIAIDS and malaria, environmental sustainability and global partnership for development. (The UN Millenium Goals Website 2010)

In the sustainable urban development debate, until recently, social sustainability aspects were commonly only "added-on" as useful disciplinary tools to promote the message of other disciplines (i.e. economics, ecology) (McKenzie 2004); however discussions revolving around concepts such as equity and environmental justice (Agyeman et al. 2004, Haughton 1999, Polese \& Stren 2000) have strengthened the relevance of social aspects in this debate. Similarly, within companies social sustainability goals are becoming more relevant and common, as is indicated by an increasing regard to corporate social responsibility. In the past, environmental management systems, design for environment, and life cycle assessments, among others, were often used by companies to address environmental sustainability aspects. In earlier reviews of tools for assessing sustainability there is a notion that tools covering social issues are or have been largely lacking, especially product-related tools (Ness et al. 2007; Levett-Therivel 2004), but there is continuing development in this field (e.g. Benoït et al. 2010; ISO 2009), and a number of methods and tools for assessing and reporting on social sustainability aspects are emerging (e.g. AccountAbility 2008; Social Accountability 2008; GRI 2007).

\subsection{Urban Development perspectives}

The mounting research on the ability of cities to sustain and promote good quality of life for its citizens is, perhaps, a result of the realization that the rapid pace of urbanization worldwide provides challenges and opportunities for promoting a more sustainable pattern of development. However, although the general sustainability debate has been ongoing for quite some time, it was not until the 1990s that it was commonly applied to cities (Hardoy et al. 2001: 339). While concerns with principles of harmonious relationships between humans, their settlements and the natural environment have for a long time been central to city planning (Blowers 1993, Hall et al. 1993), only more recently the opportunity that urban areas provide for understanding aspects of nonsustainability and how they could be addressed have become more explicit.

As with the more general debate, initially the interpretations of sustainability in the context of cities concentrated on a narrower 'ecological perspective' (Blowers and Pain 1999). This approach led to focus on the minimizing of pollution, depletion of energy and other resources, and adverse effects on the living environment. In the early debate a 'sustainable city' was associated with efficient solid waste management and recycling, reduced car dependency and greater use of alternative modes of transport: i.e. a city that was able to limit its ecological footprint (Bromley et al. 2005). Currently, however, issues 
such as social cohesion, cultural values, economic stability and growth, access to employment, services and education, health and well-being - are all considered to be relevant (ODPM 2003).

Promoting social sustainability issues within the urban development context is largely assumed to be a role of the public sector, and more specifically local authorities; but other groups such as politicians, party-networks, lobby groups, business interests, landowners, developers and residents also have responsibilities in that complex process of governance (Healey 2007). In practice however, there is no single explicit actor assigned with the role of promoting social issues, and often it is assumed that such issues are already embedded in higher level policy documents and thus there is little need for those planning for urban development projects to consider social sustainability in great detail.

Some have suggested that to promote social sustainability, the development of urban areas should improve the quality of life for all people and at the same time foster an environment that encourages integration whilst allowing for culturally and socially diverse groups to cohabit (Polese and Stren 2000:15-16). Colantonio and Dixon argue that it "concerns how individuals, communities and societies live with each other and set out to achieve the objectives of development models which they have chosen for themselves, also taking into account the physical boundaries of their places and planet earth as a whole " (2009:18). In cities of western industrialized countries the sustainability agenda has been powerfully influenced by the compact cities' debate, which suggests that there is a strong link between urban form and sustainability (Haughton and Hunter 1994, Burton 2000, Hall 2001).

Other authors have reviewed and analysed main characteristics or features of social sustainability rather than attempted to formulate a general definition. In Table 1 we present a summary of common aspects that characterize the debate in the urban context. The table was compiled based on a review of selected academic and policy literature, with the ambition of highlighting key aspects, rather than being a neverending and all-embracing list. Some caution is required in any such compilation; although all references deal with urban development issues, their focus and scope is not the same. Whilst RESCUE (2005) and Colantonio and Dixon (2009) reflect on urban redevelopment, Dempsey's analysis is broader in scope. The aspects listed are also sometimes interpreted in different ways by the various authors, as illustrated by the use of "Equal Opportunities" - RESCUE suggest it to be related to access to benefits, resources and information, whereas Littig and Griessler use it in relation to access to education. In addition, to keep the list short and focused, some of the aspects suggested by source authors have been grouped, as is the case of "Cultural Heritage", which is understood to include cultural traditions (Dempsey et al. 2009), identity and culture (Colantonio \& Dixon 2009) and cultural dynamism (Baines \& Morgan 2004). Thus the aspects listed are a grouping of main subjects and core principles that provide an overview of the key aspects of interest for social sustainability. 
Social Sustainability: aspects in the urban context

- Accessibility (e.g. access to employment, open spaces, local services, resources)

- Social capital and networks

- Health and well-being

- Social cohesion and inclusion (between and among different groups)

- Safety and security (real and perceived)

- Fair distribution of income, employment

- Local democracy, participation and empowerment (community consultation)

- Cultural heritage (e.g. local heritage and listed buildings)

- Education and training

- Equal opportunities and equity

- Housing and Community Stability

- Connectivity and movement (e.g. pedestrian friendly, good transport links)

- Social Justice (inter and intra-generational)

- Sense of place and belonging

- Mixed use and tenure

- Attractive public realm

- Local environmental quality and amenity

Table 1: Aspects identified by authors in the review of urban sustainability literature. Sources include: Baines \& Morgan 2004, Colantonio, 2007 Colantonio \& Dixon 2009, Dempsey et al. 2009, Littig \& Griessler 2005, Cuthill 2009, RESCUE 2005.

Furthermore, these aspects are not necessarily new to the urban development debate. Some of them were, for example, considered as early as the $19^{\text {th }}$ century in the Garden City movement (Howard 1902) and also in the subsequent social (or public) housing projects throughout Europe (Scanlon \& Whitehead 2008). The main difference is, perhaps, that the current debate on social sustainability aspects in urban areas recognizes that social aspects cannot be dealt with in isolation; instead, they need to be considered as part of the wider sustainability debate, but also in a local context.

\subsection{Company and Product perspectives}

Looking at social sustainability from another perspective, and focusing on companies and their products (goods and services) it is clear that there has been a similar discussion to the one outlined for urban development above. Environmental aspects have been up on the agenda for some time, and are even used for the marketing of products and companies, but social sustainability aspects have only recently been introduced more broadly in companies - perhaps due to the increasing demand and pressure from NGOs and customers for companies to address negative social impacts related to their activities and products. In this section, company and product perspectives on social sustainability are discussed; first in general and thereafter the ICT sector is used as an example. Products are considered using a life cycle perspective, and thus, supply chain, end-consumer products and their use as well as their disposal are part of the productrelated social sustainability discussion. 'Companies' are regarded as objects in themselves, i.e. considering their internal social sustainability aspects. However, they are 
also seen as actors with the potential to address these aspects in relation to the company itself or the products (as objects) and promote change.

As companies and products are diverse, key social sustainability aspects will most probably differ within a range of companies. In addition, outside stakeholders may consider it relevant to address yet other social aspects for a specific company or product. To avoid drifting into what could be a very convoluted list of social sustainability aspects from a company perspective, we here consider some common initiatives that highlight topics for companies more generally. These initiatives include the Global Compact (The UN Global Compact Website 2010), OECD guidelines for multinational enterprises (OECD 2008) and forthcoming guidelines for the Social Responsibility (SR) of organizations (ISO 2009). In addition, the current development of a methodology for social life cycle assessment (S-LCA) has also been used as the basis for the discussion on product-related social sustainability (Benoït and Mazijn 2009).

Corporate Social Responsibility (CSR), is increasingly addressed by companies, and provides a starting point for understanding social sustainability aspects in the context of companies. The forthcoming Guidelines for Social Responsibility in organizations and businesses (ISO 2009) propose seven core subjects that should be addressed by organizations: organizational governance, human rights, labour practices, the environment, fair operating practices, consumer issues, community involvement and development. It is noted that health and safety, economic aspects and gender issues are included within some of these core subjects (ISO 2009). Also, the Global Reporting Initiative (GRI) provides a framework for the reporting of businesses' and organizations' sustainability performance (GRI 2007). There the social performance indicators are grouped into the areas of: Labor Practices and Decent Work, Human Rights (focusing on workers and suppliers/contractors), Society (focusing on communities), and Product Responsibility (focusing on customers).

Turning from the company perspective to products, a life cycle approach is often used (at least for environmental issues), and this broadens the scope as well as increases the complexity of the discussion. Using a life cycle perspective adds to the list of stakeholders who should be included in the discussion of relevant aspects. These stakeholders are often at different localities and sometimes also in different time-frames (i.e. effects on future generations).

Some products may themselves enable sustainable development and contribute towards achieving sustainability, even though the overall effects are often not clear-cut. An example from ICT: from a user perspective, access and inclusion in different networks and interest groups (here through possibilities for communication) are important and could be directly facilitated by ICT; on the other hand it may be argued that integrity and security could be put at risk and that the divide between privileged and non-privileged (or rather those with access to ICT and those without) may increase rather than decrease. These kinds of aspects need to be addressed when social sustainability is discussed in relation to the stakeholder group of users. Adding a life cycle perspective, including production and disposal of ICT products, other potential social sustainability aspects become relevant, as for instance labour practices and community relations in mining and 
manufacturing.

Table 2 compiles a summary of common aspects that characterize the current discussion about the social dimension of sustainability in relation to companies and products. The compilation is based on a review of a selected academic and policy-oriented literature. The references have different scope and purpose and do not necessarily provide a directly comparable set of aspects. Thus Table 2 is an overview, a selection and in some cases an aggregation of the key principles, core subjects, subcategories etc as suggested in the literature. It can be noted that the guidelines on S-LCA (Benoït and Mazijn 2009) provided several specific subcategories for local community issues, for example related to whether companies contribute to delocalization and migration, affect access to material resources or engage with the local community. The ambition here has been to list key aspects rather than to provide a comprehensive list. Therefore, not all aspects suggested in the literature have been included in the table, as is the case of, for example, social cohesion, which is considered a subcategory of Community involvement and development in the draft ISO standard document (ISO 2009:62).

Social Sustainability: some aspects in the company and product context

- Equal opportunities

- Education and training

- Governance

- Health and safety

- Employment

- Security

- Human Rights (e.g. forced labour, child labour, freedom of association)

- Indigenous rights

- Labour practices (e.g. fair salary, working hours, social benefits to employees)

- Fair operating practices (e.g. anti-corruption, fair competition and supplier relationships)

- Cultural heritage

- Community involvement and development (e.g. accessibility, community engagement, delocalization and migration)

- Consumer/Product responsibility (e.g. satisfaction, privacy, complaints practices)

- Technology development

Table 2: Aspects identified by authors in the review of literature. Sources include: Benoït and Mazijn 2009, The UN Global Compact Website 2010, GRI 2007, ISO 2009, Jørgensen et al. 2008, OECD 2008.

Human rights is a broad theme and could be argued to cover several of the other aspects, e.g. equal opportunities, employment and security. Similarly, health and safety may be closely connected to other aspects such as labour practices, education and training and human rights.

\section{Discussion}

\section{Similarities and Differences}

The review above considered how social sustainability is defined and discussed from the 
perspectives of urban development as well as that of companies and products. A number of similarities between the fields can be noted: in both cases, social sustainability discussions have followed an earlier focus on environmental sustainability, and in neither of them there is an agreed definition for it. The review also revealed that, whilst exploring the meanings of social sustainability, there is very little literature overlap between the fields, with Bruntland's (WCED 1987) definition being one of the few exceptions. Also, in both fields there is an underlying normative nature to the sustainability debate, which sets out visions or targets for how things ought to be, and/or assumes that the aspects and definitions suggested will indeed promote positive change.

A closer look at the tables ( 1 and 2 ) shows significant overlap of aspects relevant to the social sustainability debate from the two perspectives of urban development and company and products. These include health, education, security, safety, governance and public involvement issues and equal opportunities. However, it also shows a number of field specific aspects such as technology development or attractive public realm. It should be noted that similar wording by various sources does not necessarily mean that the aspects are understood or used in the same way throughout the literature. The aspects listed are often interpreted and defined in more detail as well as in varying ways by different researchers and practitioners, highlighting the context dependency of the social sustainability debate.

To illustrate: within the urban sustainability debate "Cultural Heritage" can be related to the need to retain existing buildings with historical value, or the ability to engage with existing communities to ensure the history of an area is preserved over time, but it could also be related to people's cultural identity (Colantonio \& Dixon 2009). The same aspect of "Cultural Heritage" considered from a company and product context, could mean something very different such as the possibilities a specific product may provide to increase accessibility to knowledge about specific cultural traditions; or that relevant organizational information is provided to members of communities affected by production activities in their spoken language(s) (The UNEP SETAC Life Cycle Initiative Website 2010). Thus, despite initial apparent similarities, aspects can be understood in different ways depending on the context in which they are being considered. However, the core idea remains the same even though specific issues and relevant measures might differ.

\section{Field specific aspects}

Aspects that are specific to urban development are mostly related to physical factors; to the city and its buildings, its infrastructure etc. These include connectivity and movement (e.g. pedestrian friendly design, good transport links), mixed use, local environmental quality and amenity (i.e. access to green and open areas, air quality, etc.), urban design (e.g. maximized natural light, attractive and safe public realm), decent housing provision (e.g. mixed tenure, residential stability versus high turnover), sense of community and belonging. It could however be argued that, rather than being aspects on their own, these are practical ways in which social sustainability goals can be fostered in cities or urban areas. Thus, improvements in connectivity and movement patterns (such as new pathways) may provide better accessibility. The promotion of mixed use in brownfield 
regeneration areas might lead to improved safety and security and investment in local environmental quality and amenity has implications for health and well-being. These are aspects on different hierarchical levels rather than incompatible aspects specific to the field. Therefore, context-dependent aspects on more detailed levels will need to be discussed on a case-by-case basis.

The aspects which were found specific to companies and products were to a large extent related to the production (or disposal) and included labour practices (e.g. fair salary, working hours, social benefits to employees) and human rights related to labour issues (e.g. forced labour, child labour, freedom of association); or related to other company activities, i.e. fair operating practices (such as anti-corruption and fair competition) and product responsibility. However, one could argue that in practice many of these aspects are also addressed more generally within the urban development debate, under the headings of equal opportunities, equity, health and well-being.

\section{Life cycle approach}

Another apparent dissimilarity between the urban development and the company and product approach to social sustainability is the way in which the latter may comprise a life cycle approach which considers implications for communities in which raw materials are produced, users as well as considerations for end-of-life disposal. Although currently S-LCA has only been applied to a very limited extent, there is an increasing debate on the responsibilities for supply chain related issues as well as those related to disposal activities. In addition, S-LCA methodology at the moment only covers the end-user social sustainability aspects (which may be highly product specific) in a limited manner (Benoït and Mazijn 2009).

On the other hand, the social sustainability debate within urban development focuses mostly on issues relevant to end-users, the communities that currently live in or will use the urban areas, with little or no regard to life cycle approaches. There are exceptions however, and at times urban developments might include considerations/requirements about the origin of construction's raw materials, or rules of engagement with employees working in the construction phase. Although a life cycle approach adds further complexity to an already complicated topic, we suggest that urban development projects could benefit from a more explicit use of life cycle thinking, at least in the strategic stages, to aid in the scoping and screening of risks and potential negative social impacts. It is however also important to consider the context and time-frame of such projects, and what is (or is not) within the spheres of influence of the actors involved, before using lifecycle approaches.

\section{Key themes}

Despite disciplinary variations in interpretations and understandings of specific aspects of the social sustainability debate as illustrated above, there seems to be a common underlying understanding that social sustainability has to do with improving or maintaining the quality of life of people. In order to strengthen the understanding of core issues related to social sustainability we suggest that aspects could be aggregated under a few key themes. This is suggested to enable the quick assimilation of overall social sustainability goals despite context dependent interpretations and specifications. In this 
vein, within the urban debate, Dempsey et al. (2009) suggest social sustainability to revolve around two core themes: 'social equity' and the 'sustainability of community' with the later being connected to social cohesion and social capital, including measurable aspects such as participation, pride/sense of place and safety and security. Guidelines and methodologies for S-LCA suggest that end-points of assessment should consider 'areas of protection', proposing human well-being or fairness of relationships and human capital (or different types of societal capital) and cultural heritage as key issues (Benoît and Mazijn 2009:71; Jørgensen 2010:14). We, however, suggest that another possibility would be to use the concepts of social capital, human capital and well-being as key themes, as they seem to synthesize well both the individual and collective issues that are relevant for social sustainability.

The literature discussing well-being, social and human capital is extensive (Kiefer 2008, Ryan \& Deci 2001, Portes 1998, Putnam 1993). In short, however, human capital refers to an individual's personal abilities, or the sum of one's own skills, experiences, knowledge and competences (Becker 1993); social capital is connected to relational aspects where mutual trust and reciprocity exist (Baker 2000:1-2, Coleman 1990, Grootaert 1998) and it can be understood as features of social organizations or groups (such as social norms, codes of conduct, knowledge, trust, etc) that facilitate collective action and regulate the interactions among people and institutions. Well-being relates to the state of being or doing well in life, being happy, healthy, or prosperous (The OED Website 2010), it tends to be a broad and encompassing concept "that takes into consideration the whole person. Beyond specific physical and/or psychological symptoms related to health, wellbeing should include context-free measures of life experiences (e.g., life satisfaction, happiness)" (Danna \& Griffin 1999:364). At times, 'health' may also be defined more widely, as for example by the World Health Organization: "Health is a state of complete physical, mental and social well-being and not merely the absence of disease or infirmity" (The WHO Website 2010). However, as health is often not perceived with this wide frame, here the wording well-being is used for one of the key themes.

Whilst the key themes suggested are broader in scope than the aspects listed in tables 1 and 2, the relationship between key themes and aspects is not necessarily hierarchical, but aspects will help characterize and specify in more detail the key themes within a given context. Also, the aspects can influence more than one of the key themes simultaneously, as the key themes are not strictly unconnected. Thus improvements in, for example, human capital may also have an impact on well-being and may affect social capital. These key themes may indeed also impact underlying aspects such as for example health or fair operating practices.

To exemplify: physical and mental health is an important contributor to people being satisfied with their life and thus it is embedded in the key theme of well-being. However health can also influence the ability of people to study or develop new skills and knowledge, whilst ill-health can create barriers for people to develop social relations or be active participants in the community where they live, etc. But at the same time illnesses can also contribute to new opportunities for relationships between people to emerge, and the personal experience of an illness in itself also could have positive human capital implications. These examples indicate that the relation between key theme and 
aspects can be complex. However, within a well-defined context or project, such relations could be simplified. We suggest that the advantage of introducing key themes is that the overall meaning of social sustainability could be assimilated more quickly, providing a platform from which a case-specific problem formulation and context dependent aspects and indicators can be developed. This may reduce the risk of some stakeholders highjacking specific aspects and focusing on narrow issues of social sustainability to pursue their own interests. Also the choice of wording for the suggested key themes is not clearcut, but the three themes suggested here are believed to provide a relevant scope.

\section{Stakeholders - Agents for change and Agents affected}

Another difference between the urban development and company and product's approach to social sustainability is one that is related to stakeholders, to what actor is responsible for formulating the aim and for taking action (agents for change). In urban development these agents for change are often found in the public sector; however, rarely one specific actor is assigned with the explicit responsibility for promoting social issues. In contrast, companies are more explicitly considered responsible (or the agent for change) for promoting social sustainability, as is indicated by the growing importance of corporate social responsibility policies within companies. In addition, actions related to companies and products are generally led by private interests, but could also be influenced by customers, who may (or may not) be from the public sector. In both fields, 'agents for change' may have public, corporate or individual/personal interests, and these interests will influence the interpretations of social sustainability within these groups. In the draft ISO standard on social responsibility it is noted that "the sustainability of an individual organization may, or may not, be compatible with the sustainability of society as a whole..." (ISO 2009: 10). Thus, for companies social sustainability issues might be limited to those directly linked to the company, or have a broader scope. However, more overarching societal aspects that are often highlighted in urban development projects such as social cohesion and inclusion - may be less in focus for companies. Hence the need of a public authority and mechanisms that promote the internalization of companies' effects on the community.

In addition to the 'agents for change' in a particular project, there are also those who can be grouped as 'affected by change' (some stakeholders being both). Each of these stakeholders may find some aspects of social sustainability more relevant than others, and their interpretations of the meaning of individual aspects will often reflect their own agendas, and thus agreement on key aspects within a specific context might be difficult. One possible way of handling this problem is to repeatedly subject each aspect of social sustainability discussed in this paper to a series of questions such as: What? (the aspect); Why? For Whom? (target group/stakeholder) How? (strategies) By whom? (agent for change) When? (timing). The systematic answering to these questions should help provide an indication of the priorities for action in a particular project/context. To exemplify, a company aiming at improving its social sustainability may ask: What? Education; Why? To improve or maintain skills; For Whom? For employees of the company; How? By providing training opportunities; By Whom? By the employers; When? Once a week during working hours. Of course, the individual aspect could have several answers to each of the following questions. 
This line of questioning should then be repeated for health, security, participation, etc in order to help narrow down what is relevant for social sustainability in that particular context or project. If it is not possible to satisfactorily answer the questions above for a set of aspects that may be a sign that these aspects are not as relevant to the particular project, or that they are outside the sphere of influence of the stakeholders involved. In this case, the use of life cycle approaches in the screening phase could be helpful to ensure that all relevant stakeholders are included in the discussion.

\section{Social sustainability in practice}

The discussion in this paper has proposed aspects that should be considered when discussing social sustainability without framing how they should perform, as this is something that is context dependent and needs to be specified in relation to a specific project. Thus, whilst this paper points out that "Security" is an important aspect that contributes to social sustainability, the interpretation and goal setting for what security means in practice will depend on the context and priorities of a particular project. Future research could investigate how these aspects can be put into practice by stakeholders and practitioners.

Furthermore, the three key themes suggested may be used as part of the scoping and problem formulation in a specific project, in order to provide a common platform and encourage a wide perspective which should thereafter be narrowed down aided by the questioning of specific aspects for a more detailed picture in relation to the specific context. In future, research could look at ways in which key themes and more specific aspects are related, possibly proposing a tool for quantitative or qualitative analysis of these in relation to a specific project.

\section{Conclusions}

The concept of social sustainability is increasingly being analysed and considered both by academics and practitioners. Whilst broad definitions are often vague, a better understanding of the aspects that underpin the concept within different fields could facilitate the translation of this complex concept. This paper has reviewed academic and policy literature on the concept from the contrasting perspectives of urban development and company and product. Based on this review we found that whereas on the one hand many aspects are similar and there seems to be an underlying common understanding of what social sustainability is, on the other hand it became evident that context dependency influences the relevance and interpretations of the more detailed aspects of social sustainability. Thus, the local context and priorities will be critical to establish who is the agent for change and what are the relevant aspects to be included.

While comparing and contrasting the fields it also became clear that a systems' perspective and life cycle approach could be part of scoping to avoid sub-optimizations and possible negative social impacts. Currently the life cycle approach to social sustainability is more commonly discussed for products, but urban development initiatives might benefit from such an approach too. This does not have to mean detailed efforts with in-depth quantitative life cycle assessment. In most cases, it may be sufficient to consider a qualitative life cycle perspective for the scoping and screening of 
risks.

We have also suggested that the aggregation of aspects of social sustainability into key themes may be beneficial for promoting an understanding of the overall concept and for putting specific objectives and activities in perspective. However, care should be taken in promoting such generalizations, as in practice, local/context dependant priorities and conditions may influence which aspects of social sustainability are most relevant. Thus, the overarching themes should be used alongside the detailed aspects, helping to focus the scoping and problem formulation in a particular context: be it a product, a company or a neighbourhood redevelopment project. Hence the importance of early involvement of all stakeholders to help define and identify what the local priorities and conditions are, influencing the choice of key aspects. (Geibler et al.2006; Benoït et al. 2010). Future research could explore further the relations between key themes and more specific aspects of social sustainability, using quantitative and qualitative methods. 


\section{References}

AccountAbility. 2008. AA1000 Accountability Principles Standard 2008. Available at http://www.accountability.org/uploadedFiles/publications/AA1000APS\%202008.pdf [9 June 2010]

Agyeman J, Evans B. 2004. 'Just Sustainability': the emerging discourse of environmental justice in Britain? The Geographical Journal Vol. 170 (2) pp. 155-164.

Baines J, Morgan B. 2004. Sustainability Appraisal: A Social Perspective. In Sustainability Appraisal. A Review Of International Experience And Practice, Dalal-Clayton B And Sadler B, (Eds), First Draft of Work in Progress, International Institute for Environment and Development: London; chapter 5.

Baker W. 2000. Achieving success Through Social Capital (University University of Michigan Business School Management Series). Jossey-Bass: New York.

Barbier EB. 1987. The concept of sustainable economic development, Environmental Conservation Vol. 14, (2), pp. 101-110. DOI: 10.1017/So376892900011449

Becker GS. 1993. Human Capital: A Theoretical and Empirical Analysis with Special Reference to Education $3^{\text {rd }}$ Edition. The University of Chicago Press:Chicago.

Benoït C, Mazijn B. (eds). 2009. Guidelines for Social Life Cycle Assessment of Products. Social and socio-economic LCA guidelines complementing environmental LCA and Life Cycle Costing, contributing to the full assessment of goods and services within the context of sustainable development. UNEP-SETAC Life-Cycle Initiative. ISBN 978-92-807-3021-0

Benoït C, Norris GA, Valdivia S, Ciroth A, Moberg A, Bos U, Prakash S, Ugaya C, Beck T. 2010. The Guidelines for Social Life Cycle Assessment of products: Just in time! International Journal of Life Cycle Assessment, 15 : 2 : 156-163. DOI 10.1007/s11367-009-0147-8

Blowers A, Pain K. 1999. "The Unsustainable City?". In Unruly Cities? Order/Disorder (Understanding Cities), Brook C, Mooney G, Pile S (eds). Routledge:London; 222-267.

Blowers A. 1993. The time for change. Planning for a Sustainable Environment. A report by the Town and Country Planning Association. Earthscan: London.

Bromley RDF, Tallon AR, Thomas CJ. 2005. City Centre Regeneration through Residential Development: Contributing to Sustainability. Urban Studies 42 (13) pp. 2407-2429.

Burton E. 2000. "The Compact City: Just or Just Compact? A Preliminary Analysis", Urban Studies, 37, 11, 1969-2001

Colantonio A, Dixon T. 2009. Measuring Socially Sustainable Urban Regeneration in Europe. EIB Final Report. Oxford Institute for Sustainable Development (OISD). Oxford Brookes University: Oxford.

Colantonio A. 2007. Social Sustainability: An exploratory analysis of definitions, assessments methods, metrics and tools. Working Paper series. Oxford Institute for Sustainable Development (OISD). Oxford Brookes University: Oxford.

Coleman J. 1990. Foundations of Social Theory. Harvard University Press: Cambridge.

Connelly S. 2007. Mapping Sustainable Development as a Contested Concept. Local Environment, 12(3): 259-278.

Cuthill M. 2009. Strengthening the 'Social' in Sustainable Development: Developing a Conceptual Framework for Social Sustainability in a Rapid Growth Region in Australia. Sustainable Development DOI: 10.1002/sd.397

Danna K, Griffin RW. 1999. Health and Well-Being in the Workplace: A Review and Synthesis of the Literature. Journal of Management 25(3), 357-384.

Dempsey N, Bramley G, Power S, Brown C. 2009. The social dimensions of sustainable development: defining urban social sustainability. Sustainable Development. DOI: $10.1002 / \mathrm{sd} .417$ 
Elliot JA. 1999. Introduction to Sustainable Develoment. $2^{\text {nd }}$ Edition. Taylor \& Francis: New York.

Faucheux S,O'Connor M, Van der Straaten J. 1998. Sustainable Development: Concepts, Rationalities and Strategies. Dordrecht: Kluwer Academic Publishers: 1-18.

Geibler JV, Liedtke C, Wallbaum H, Schaller S. 2006. Accounting for the social dimension of sustainability: experiences from the biotechnology industry. Business Strategy and the Environment 15, 334-346.

GRI. 2007. Sustainability Reporting Guidelines. Version 3.0. Global Reporting Initiative. Amsterdam. Available at http://www.globalreporting.org/NR/rdonlyres/EDgEgB36-AB544DE1-BFF2-5F735235CA44/0/G3 GuidelinesENU.pdf [9 June 2010]

Grootaert C. 1998. Social Capital: The Missing Link? Social Capital Working Paper Series no. 3. The World Bank.

Hall P. 2001. Sustainable cities or town cramming? In Planning for a Sustainable Future, Layard A, Davoudi S, Batty S. (eds). Spon: London; 101-114.

Hall D, Hebbert M, Lusser M. 1993. The Planning Background. In Planning for a Sustainable Environment, Blowers A (ed). A Report by the Town and Country Planning Association. Earthscan: London; 19-35.

Hardoy J, Mitlin D, Satterthwaite D. 2001. Environmental Problems in an Urbanizing World. London: Earthscan.

Haughton G. 1999. Environmental Justice and the Sustainable City. Journal of Planning Education and Research 18: 233-243.

Haughton G, Counsell D. 2004. Regions, Spatial Strategies and Sustainable Development. London, Routledge.

Haughton G, Hunter C. 1994. Sustainable Cities. Regional Studies Association: London.

Healey P. 2007. Urban Complexity and Spatial Strategies: Towards a relational planning for our times. The RTPI Library Series. Routledge: London.

Howard E. 1902. Garden Cities of To-morrow. Swan Sonnerschein: London.

ISO 2009. ISO/DIS 26000 Guidance on social responsibility ISO/TMB/WG SR N 172 DRAFT

INTERNATIONAL STANDARD. International Organization for Standardization: Geneva.

Jabareen Y. 2008. A new conceptual framework for sustainable development. Environment, Development and Sustainability 10: 179-192.

Jordan A. 2008. The governance of sustainable development: taking stock and looking forwards. Environment and Planning C: Government and Policy 8(26), pp 17-33.

Jørgensen A, Le Bocq A, Nazarkina L, Hauschild M. 2008. Methodologies for Social Life Cycle Assessment. International Journal of Life Cycle Assessment 13(2), pp 96-103.

Jørgensen A. 2010. Developing the Social Life Cycle Assessment - addressing issues of validity and usability. PhD Thesis, Department of Management Engineering. Technical University of Denmark.

Kiefer RA. 2008. An Integrative Review of the Concept of Well-being. Holistic Nursing Practice 22(5), pp 244-252.

Koning J. 2002. Social Sustainability in a globalizing world: context, theory and methodology explored. In More on MOST: Proceedings of an Expert Meeting, Rinsum HJ van, Ruijter A de, Kazancigil A, Alagh YK, Genov N, Koning J, Siebers H. Unesco Centre: Amsterdam.

Le Heron R. 2006. Towards governing spaces sustainably: reflections in the context of Auckland, New Zealand. Geoforum 37: 441-446.

Levett-Therivel. 2004. Report to the sue-MoT consortium: Sustainable Urban EnvironmentMetrics, Models and Toolkits: Analysis of sustainability/social tools, 9 June 2004.Levett-Therivel sustainability consultants: Oxford.

Littig B, Griessler E. $\mathbf{2 0 0 5}$. Social sustainability: a catchword between political pragmatism and social theory. International Journal of Sustainable Development, Vol. 8: 1/2, 65-79 
Marcuse P. 1998. Sustainability is not enough. Environment and Urbanization, 10(2): 103-111.

McKenzie S. 2004. Social Sustainability: Towards some definitions. Working Paper Series No 27. Hawke Research Institute University of South Australia

Ness B, Urble-Piirsalu E, Anderberg S, Olsson L. 2007. Categorising tools for sustainability assessment. Ecological Economics 6o, pp 498-508.

ODPM (Office of the Deputy Prime Minister). 2003. Sustainable Communities: Building for the Future. ODPM:London.

OECD. 2008. OECD Guidelines for Multinational Enterprises. Paris: OECD Publishing.

Polese M, Stren R. 2000. Understanding the new sociocultural dynamics of cities: comparative urban policy in a global context. In The Social Sustainability of Cities: Diversity and the managemet of change, Polese M, Stren R (eds). Toronto University Press: Toronto; 3-38.

Portes A. 1998. Social Capital: Its Origins and Applications in Modern Sociology. Annual Review of Sociology 24,1:1-14.

Putnam R. 1993. Making Democracy Work. Civic Traditions in Modern Italy. Princeton University

Press: Princeton.

Redclift MR (ed). 2005a. Sustainability: Critical Concepts in the Social Sciences, four volumes Routledge: London.

Redclift MR. 2005b. Sustainable Development (1987-2005): An Oxymoron Comes of Age. Sustainable Development 13: 212 - 227. Wiley InterScience.

RESCUE. 2005. Best Practice Guidance for Sustainable Brownfield Regeneration. Edwards D, Pahlen G, Bertram C, Nathanail CP. Land Quality press on behalf of the RESCUE consortium: Nothingham.

Ryan RM, Deci EL. 2001. On Happiness and Human Potentials: A Review of Research on Hedonic and Eudaimonic Well-Being. Annual Review of Psychology 52, pp 141-166.

Sachs I. 1999. Social sustainability and whole development: exploring the dimensions of sustainable development. In Sustainability and the social sciences: a cross-disciplinary approach to integrating environmental considerations into theoretical reorientation, Egon B, Thomas J. (eds). ZedBooks: London.

Scanlon K, Whitehead C. (eds) 2008. Social Housing in Europe II. A Review of Policies and Outcomes. London School of Economics: London. Available at: http://www.Ise.ac.uk/collections/LSELondon/pdf/Social\%2oHousing $\% 20$ ll/Social Housing in Europe II. A review of policies and outcomes.pdf [15 July 2010]

Social Accountability 8000 (2008). International Standard, SAI, SA8000 ${ }^{\circledR}: 2008$, Social Accountability International: New York. Available at: http://www.saintl.org/ data/n 0001/resources/live/2008StdEnglishFinal.pdf [9 June 2010].

The OED Website 2010. (Oxford English Dictionary). http://www.oed.com/ [05 September 2010]. The UNEP SETAC Life Cycle Initiative Website. 2010. Methodological Sheets of Sub-Categories of Impact for a Social LCA. http://fri.estis.net/sites/lcinit/default.asp? site=Icinit\&page id=EDA1E98F-412F-4F51-B407-3A7E006E1B83 [20 August 2010]

The UN Global Compact Website. 2010. http://www.unglobalcompact.org [9 June 2010] The UN Millenium Goals Website. 2010. http://www.un.org/millenniumgoals [9 June 2010] The UNSD Website. 2010. http://www.un.org/esa/dsd/susdevtopics/sdt index.shtml [9 June 2010] The WHO Website. 2010. http://www.who.int/about/definition/en/print.html [7 September 2010] WCED. 1987. Our Common Future (Bruntland Report) World Commission on Environment and Development, Oxford University Press: Oxford. 